\title{
Experimental Measurement of Minority Carriers Effective Lifetime in Silicon Solar Cell Using Open Circuit Voltage Decay under Magnetic Field in Transient Mode
}

\author{
Alain Diasso' ${ }^{1}$, Raguilignaba Sam ${ }^{1,2}$, Bernard Zouma ${ }^{3}$, François Zougmoré1 \\ ${ }^{1}$ Department of physic, Laboratory of Materials and Environment, Units of Sciences and Technology, \\ University of Joseph Ki-Zerbo, Ouagadougou, Burkina Faso \\ ${ }^{2}$ Units of Sciences and Technology, Department of Physic, University of Nazi Boni, Bobo Dioulasso, Burkina Faso \\ ${ }^{3}$ Department of Physic, Units of Sciences and Technology, Laboratory of Thermal and Renewable Energy, \\ University of Ouagadougou, Ouagadougou, Burkina Faso \\ Email: alinodiass@yahoo.fr
}

How to cite this paper: Diasso, A., Sam, R., Zouma, B. and Zougmoré, F. (2020) Experimental Measurement of Minority Carriers Effective Lifetime in Silicon Solar Cell Using Open Circuit Voltage Decay under Magnetic Field in Transient Mode. Smart Grid and Renewable Energy, 11, 181-190.

https://doi.org/10.4236/sgre.2020.1111011

Received: October 14, 2020

Accepted: November 23, 2020

Published: November 26, 2020

Copyright $\odot 2020$ by author(s) and Scientific Research Publishing Inc. This work is licensed under the Creative Commons Attribution International License (CC BY 4.0).

http://creativecommons.org/licenses/by/4.0/

\begin{abstract}
This manuscript presents a simple method for excess minority carriers' lifetime measurement within the base region of $\mathrm{p}-\mathrm{n}$ junction polycrystalline solar cell in transient mode. This work is an experimental transient 3-Dimensionnal study. The magnitude of the magnetic field $\mathrm{B}$ is varied from $0 \mathrm{mT}$ to 0.045 $\mathrm{mT}$. Indeed, the solar cell is illuminated by a stroboscopic flash with air mass 1.5 and under magnetic field in transient state. The experimental details are assumed in a figure. The procedure is outlined by the Open Circuit Voltage Decay analysis. Effective minority carrier life-time is calculated by fitting the linear zone of the transient voltage decay curve because linear decay is an ideal decay. The kaleidagraph software permits access to the slope of the curve which is inversely proportional to the lifetime. The external magnetic effects on minority carriers' effective lifetime is then presented and analyzed. The analysis shows that the charge carrier's effective lifetime decrease with the magnetic field increase.
\end{abstract}

\section{Keywords}

Carrier Lifetime, Fitting, Magnetic Field, Open Circuit Voltage Decay

\section{Introduction}

The lifetime of minority carriers is an important parameter and its determina- 
tion is essential to improve solar cells high efficiency. The dark and illuminated characteristics are affected by the charge carriers' lifetime. This electronic parameter restricts the open-circuit voltage, short circuit courant and the net output power. Therefore, with the increasing interest in photovoltaic energy conversion, fresh attempts have been made in the recent past for accurate lifetime measurement. Suitability for the earlier methods for $\mathrm{p}-\mathrm{n}$ junctions, e.g. open-circuit voltage decay [1], the reverse recovery [2] [3], photoconductivity decay [4], spectral response [4] has been studied everyone with his advantages.

Among all methods, we are chosen the open-circuit voltage decay method. This method is practice for our experimental conditions. However, two methods are used to induce the initial voltage: the conventional method [1] [5] in which a current is passed through the cell from an external source such as a battery. This is the forward current-voltage decay (F.C.V.D) method. The second is to illuminate the cell using a semi-conductor by a laser [6] or a stroboscope [1] [7]; we call it the photovoltage decay method (P.V.D). In both cases, the voltage is abruptly interrupted and the voltage decay is measured on an oscilloscope. The open-circuit voltage decay technic [1] [8] is a simple non-destructive method for measuring minority carriers' lifetime in solar cells. In this method, a voltage is induced in the solar cell and is then allowed to decay under open-circuit conditions.

In this study, firstly we present the experimental set-up. Secondly, the experimental conditions will be described and assumptions made will be presented. Thirdly, the method for charge carriers' effective lifetime measurement will be explained and the results obtained will be presented and analyzed.

\section{Materials and Methods}

\subsection{Materials}

The experimental set-up is composed of: a mono-facial silicon solar cell manufactured by MOTCH INDUSTRY; a pulsed light source MINISTROB PHIWE, a digital oscilloscope TECKTRONIX model TDS 10013, a computer INTEL 586, a power supply 0 - 12V DC/6V-12V AC, a teslameter and Helmholtz Coil.

The experimental set-up is presented in Figure 1 and operating mode in Figure 2.

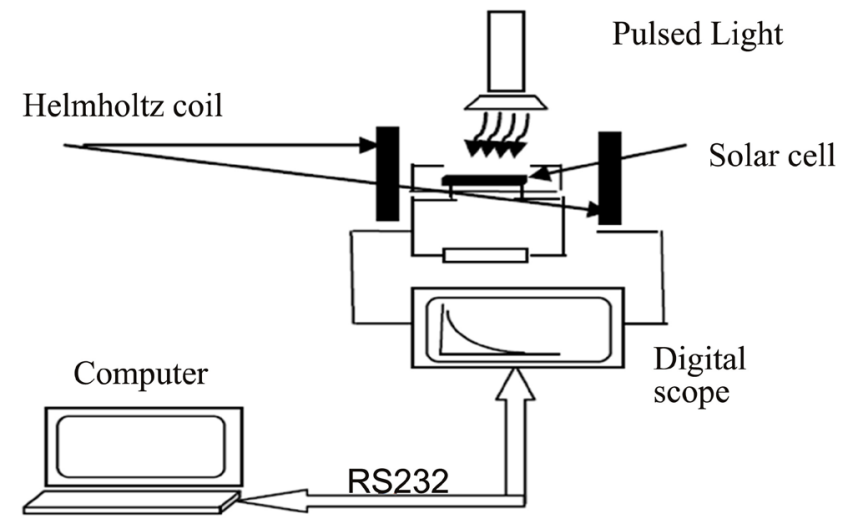

Figure 1. Experimental set-up. 


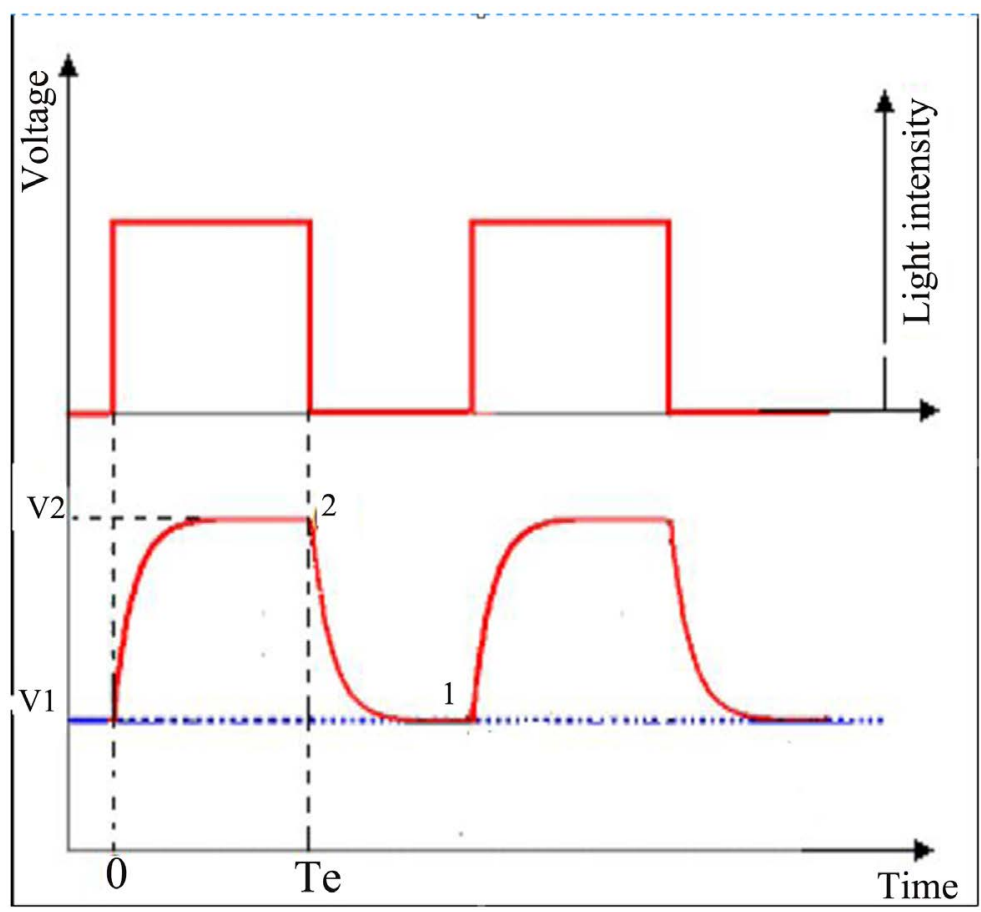

Figure 2. Operating mode.

The experimental system principle operating is the same described by Sam et al. and R. Sam et al. [9] [10]. In additional, we consider the stroboscope flash is near of AM1.5 spectrum and the solar in operating conditions where there are not others fields.

The Kaleidagraph software which is a thoughtfully designed graphing and data analysis application for research scientists permit us to convert complex data obtained during experimentation into transient curves.

\subsection{Methods}

The transient response is obtained by disturbance of steady state. While exciting the solar cell, we carry it towards a state characterized by a balance between the phenomena of recombination and generation of pairs electron-hole [10]. This stationary state defined a point1. After a duration Te (stroboscope pulse duration), the excitation is abruptly switched off; the balance between recombination and generation is so broken. A transient response appears and the solar cell towards a new stationary state: its fundamental state. This other state later defines a new point that we call 2 . The transient response corresponds to the relaxation state of the sample between two operating points 1 and 2 .

Considering the identical optoelectronic properties of all the lot of grains, then the study of phenomena of generation, diffusion and recombination of the charge carriers in the solar cell during the transient state can be described a only one grain. Figure 3 is a representation of a grain under magnetic field.

The calculation of transient voltage decay expression by using boundaries conditions and quasi-neutral base theory gives [11]: 


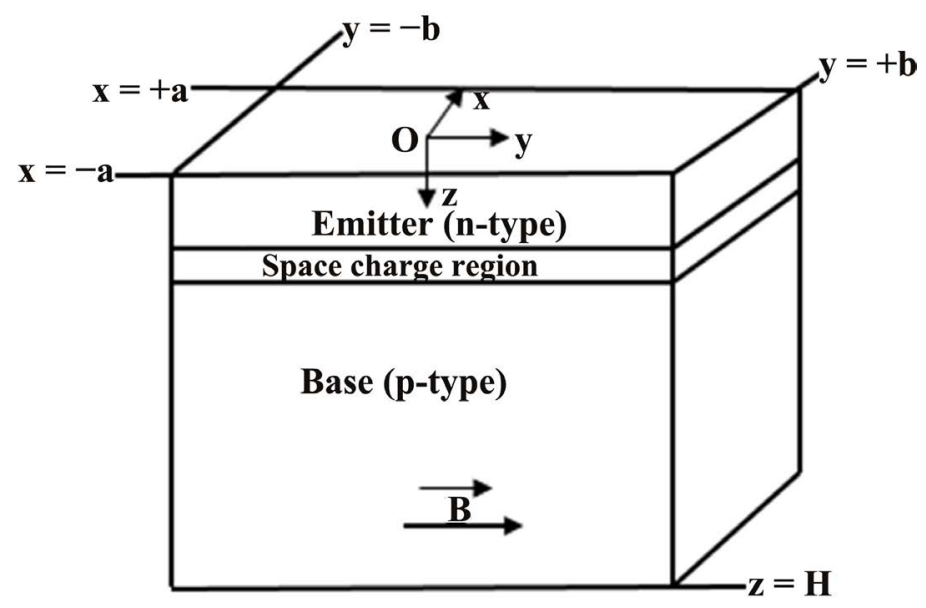

Figure 3. A sample model of grain under magnetic field.

- For exponential zone

$$
V(t)=V_{T} F c\left(k_{1}, l_{1}^{*}, \mu_{1}\right) r \exp \left(-\beta^{*}(t-T e)\right)
$$

This is a time dependent exponential decay function

- For linear zone

$$
V(t)=V_{T}\left(-\beta^{*}(t-T e)+r \ln \left(1+F v\left(k_{1}, l_{1}^{*}, \mu_{1}\right)\right)\right)
$$

This is a linear function of time with a negative slope $-V_{T} \beta^{*}$

$$
\begin{aligned}
& \left.\frac{\partial \delta(x, y, z, t)}{\partial z}\right|_{z=0}=\frac{S f}{D^{*}} \delta(x, y, z=0, t) \\
& \left.\frac{\partial \delta(x, y, z, t)}{\partial z}\right|_{z=H}=\frac{S b}{D^{*}} \delta(x, y, z=H, t) \\
& \left.\frac{\partial \delta(x, y, z, t)}{\partial x}\right|_{x= \pm a}= \pm \frac{S g x}{D^{*}} \delta(x= \pm a, y, z, t) \\
& \frac{\left.\partial \delta(x, y, z, t)\right|_{y= \pm b}}{\partial y}= \pm \frac{S g y}{D^{*}} \delta(x, y= \pm b, z, t)
\end{aligned}
$$

Equations (3)-(6) are boundaries conditions. $S f, S b, S g$ are the recombination velocity of minority charge carriers respectively at surfaces $z=0, z=H$ and $x= \pm a($ or $y= \pm b)$. $a, b$ and $H$ are the grain sizes as indicated in Figure 2.

$D^{*}, L^{*}$ are also respectively the electrons diffusion coefficient and length diffusion of charge carriers

\section{Effective Lifetime of Minority Charge Carriers' Measurement}

Our approach is based on the linear approximation of transient voltage decay because in low injection it permits to avoid impedances effects [12]. The following curve present the different zones of transient voltage curve. 
After identification of linear zone of the curve, we fit this zone and we get a linear regression line indicated in Figure 4.

In Figure 5, the linear regression line equation is found with a good correlation coefficient $\mathrm{R}$. The slope of this linear regression line is related by the effective lifetime of minority charge carriers.

$$
|m|=\frac{V_{T}}{\tau_{\text {eff }}}
$$

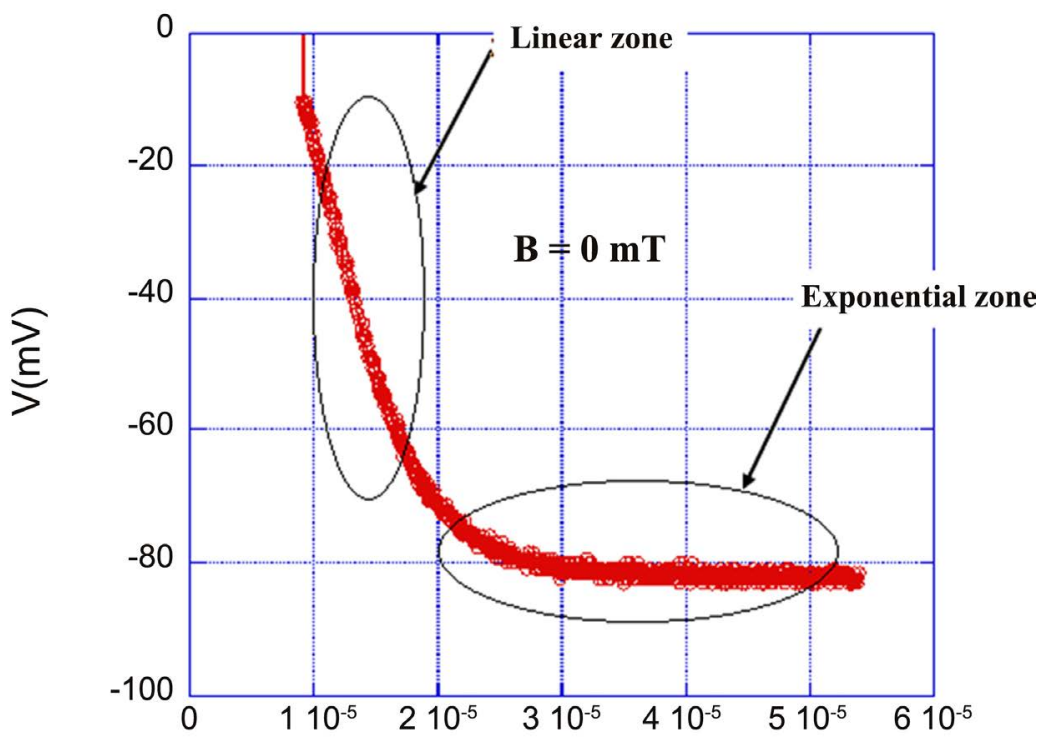

$\mathrm{t}(\mathrm{s})$

Figure 4. Voltage decay with different zones in transient state.

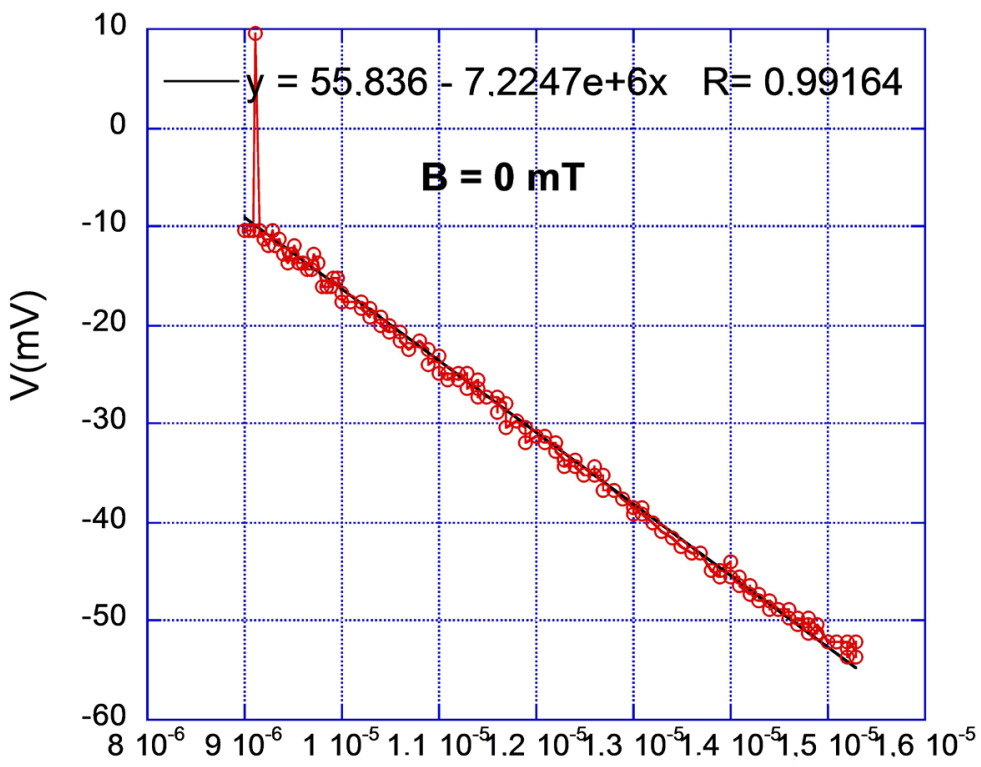

$t(s)$

Figure 5. A linear regression line with it equation. 
where $m$ is the slope of the transient voltage curve, $V_{T}$ is the thermic voltage and $\tau_{\text {eff }}$ is the charge carrier effective lifetime.

\section{Results and Discussions}

After registration of transient voltage data on digital scope, we use kaleidagraph software to make simulations. Then, we get the curves of transient voltage decay for various magnetic field values under AM1.5 spectrum (Figures 6-13).

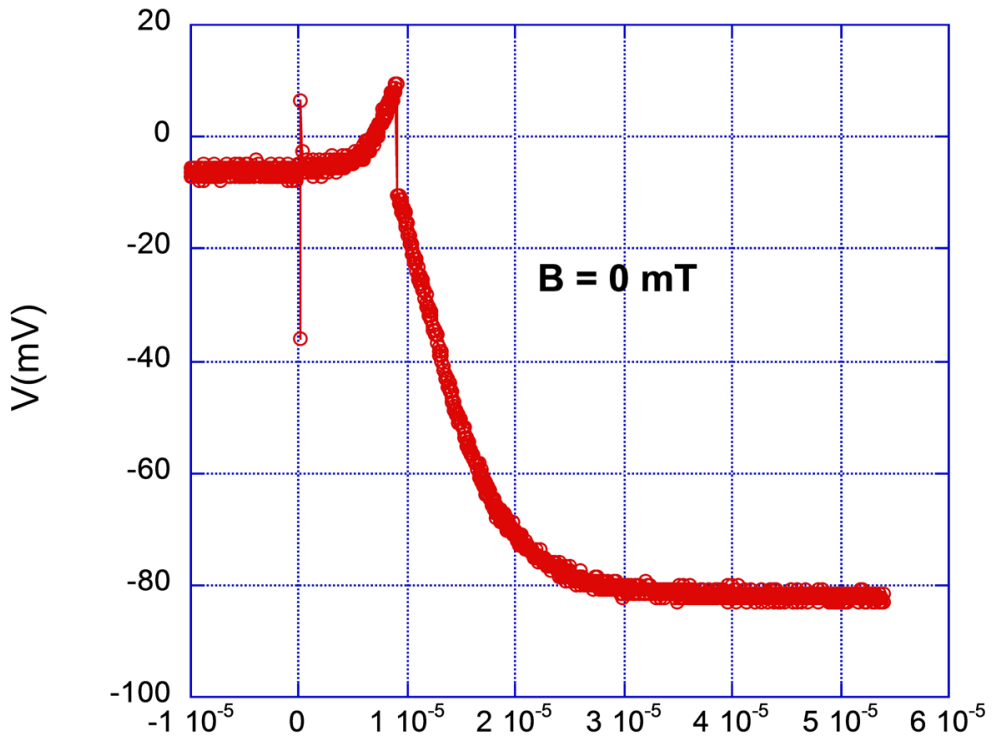

$t(s)$

Figure 6. Transient voltage decay $B=0 \mathrm{mT}$.

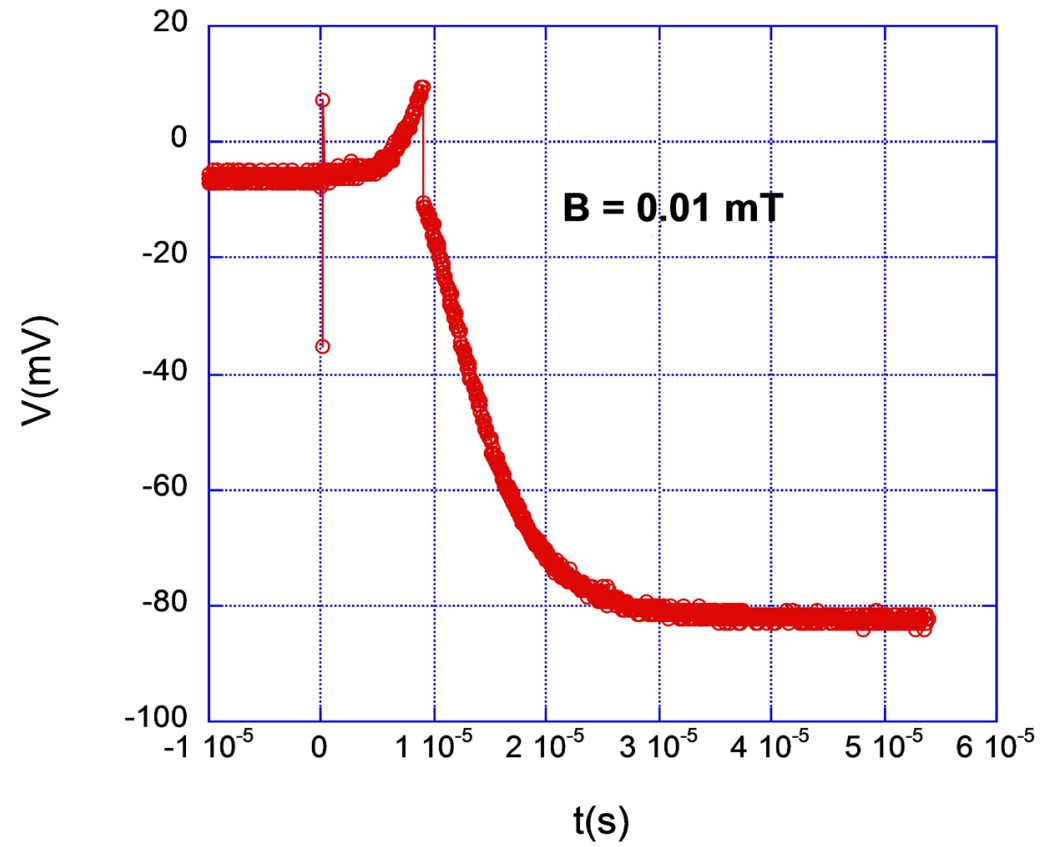

Figure 7. Transient voltage decay $B=0.01 \mathrm{mT}$. 


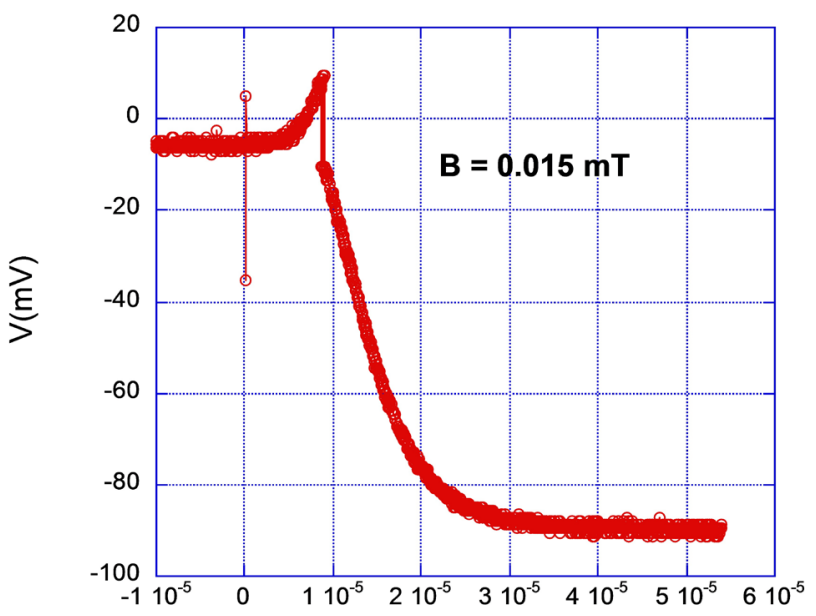

$\mathrm{t}(\mathrm{s})$

Figure 8. Transient voltage decay $B=0.015 \mathrm{mT}$.

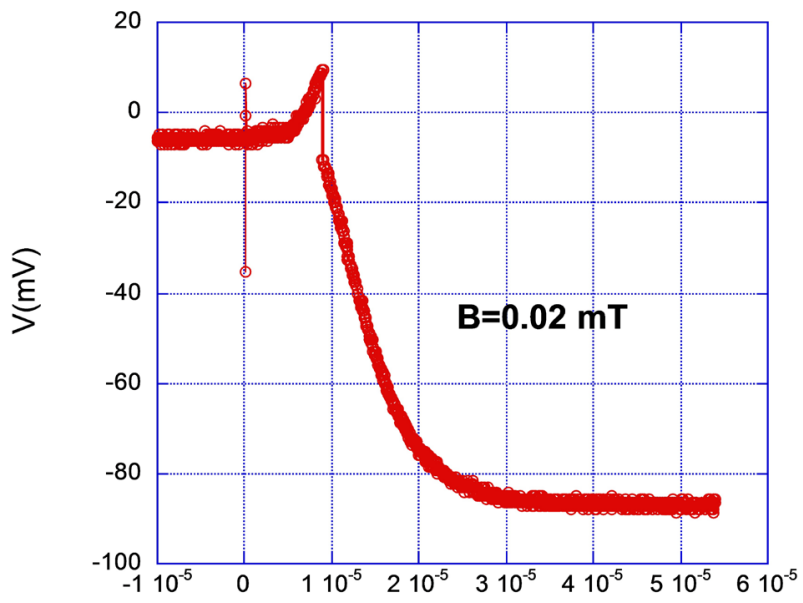

$\mathrm{t}(\mathrm{s})$

Figure 9. Transient voltage decay $B=0.02 \mathrm{mT}$.

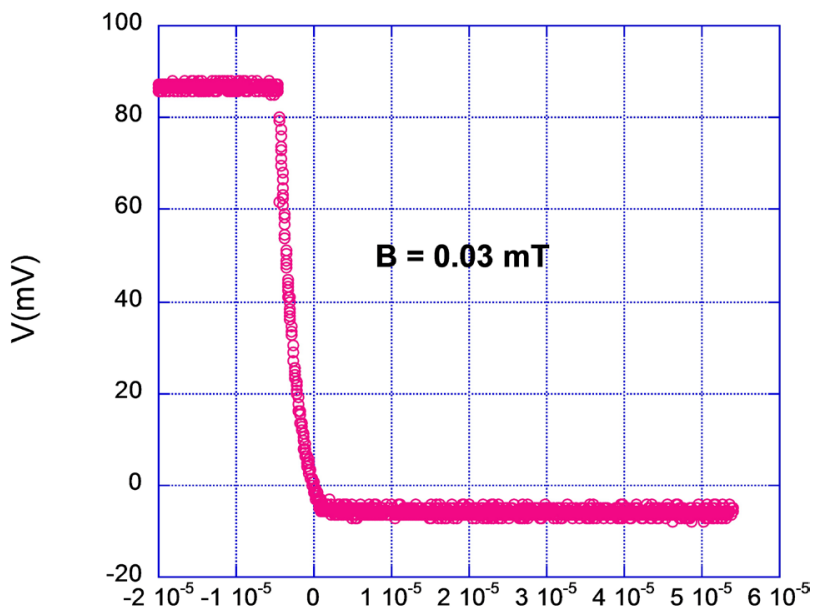

$\mathrm{t}(\mathrm{s})$

Figure 10. Transient voltage decay $B=0.030 \mathrm{mT}$. 


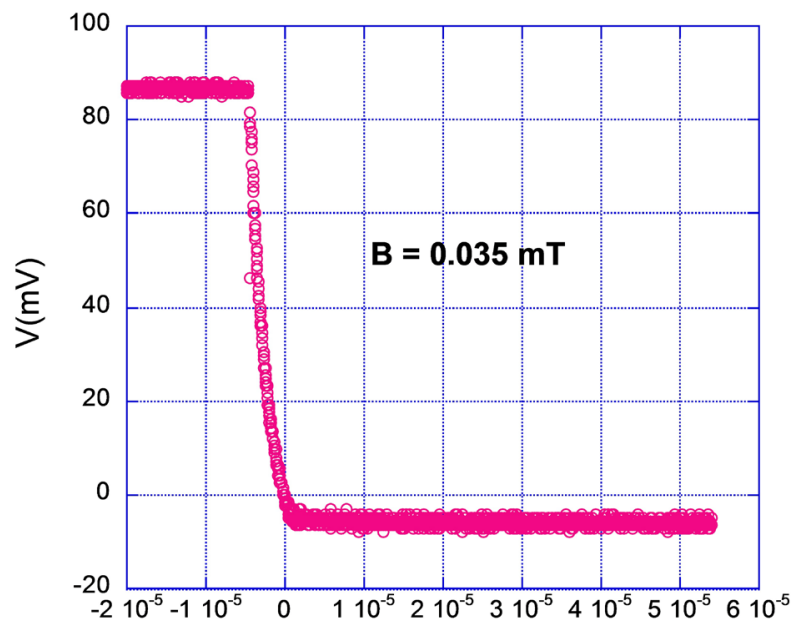

$\mathrm{t}(\mathrm{s})$

Figure 11. Transient voltage decay $B=0.035 \mathrm{mT}$.

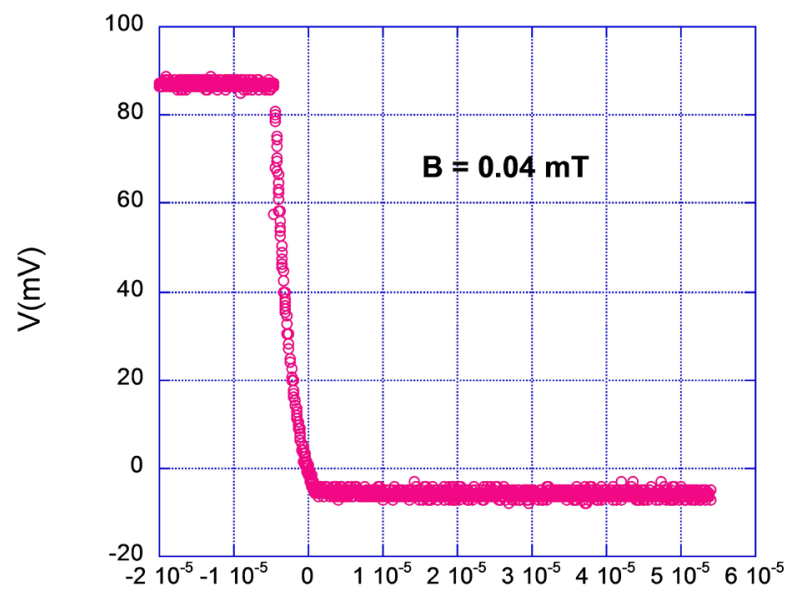

$\mathrm{t}(\mathrm{s})$

Figure 12. Transient voltage decay $B=0.04 \mathrm{mT}$.

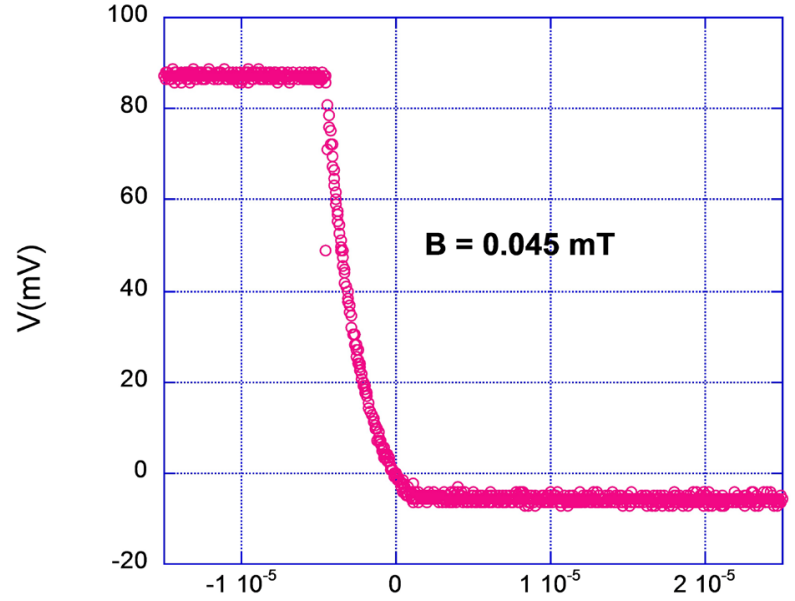

$\mathrm{t}(\mathrm{s})$

Figure 13. Transient voltage decay $B=0.045 \mathrm{mT}$. 
Table 1. Minority charge carriers effective lifetime.

\begin{tabular}{ccccccccc}
\hline$B(\mathrm{mT})$ & 0 & 0.01 & 0.015 & 0.02 & 0.03 & 0.035 & 0.04 & 0.045 \\
$\tau_{\text {eff } L}(\mu \mathrm{s})$ & 3.6 & 3.6 & 3.3 & 3.2 & 1 & 1 & 1 & 1 \\
$\mathrm{R}_{\mathrm{E}}$ & 0.9916 & 0.9927 & 0.9824 & 0.9625 & 0.9639 & 0.9727 & 0.9828 & 0.9404 \\
\hline
\end{tabular}

$R_{E}$ is correlation coefficient which show the quality of the fit.

By observations of the curves, we note two types of decay: linear decay and exponential decay. Also, we remark that for magnetic field values $B \geq 0.03 \mathrm{mT}$, the decay is very fast and the linear decay is major than exponential decay.

After the fitting of all the analyzed curves, we note that the exponential zone is minor than the linear zone. We got ideal types of open circuit transient voltage decay according to Dariwhal and Mahan conditions [7] [13]. Also, this zone of the curves doesn't present capacitance effects. The results of all transient voltage decay curves linear fitting are noted on Table 1.

The analysis of the results show that the charge carriers' effective lifetime decreases with the magnetic field. These results are in agreement with theoretical results obtained by Alain et al. [13]. However, we remark that for magnetic values $B \prec 0.02 \mathrm{mT}$, the variations are very slow. The decay becomes sudden when magnetic field values exceed $0.02 \mathrm{mT}$. Indeed, the charge carriers' effective lifetime is reduced of $67 \%$ for magnetic field values variations $0.02 \mathrm{mT} \prec B \prec 0.03 \mathrm{mT}$. This decay explain the fast recombination of charge carriers when the magnetic field increase. The extension of space charge region width with the magnetic field increase [14] traduces an important disappearance of charge carriers. Also, the decrease of diffusion length with magnetic field explains these variations of minority charge carriers' effective lifetime.

\section{Conclusion}

In this manuscript, we have developed an experimental technic of measurement of minority charge carriers' effective lifetime under various magnetic fields with air mass AM1.5. Our approach is based on the method of Open Circuit Transient Voltage Decay. From the experimental set-up described and presented, we got transient voltage decay data and used them to plot the curves. We have done a linear fit on the analyzed curves in their linear zone because this zone is major than exponential zone for all transient voltage curves and did not present impedance effects. These results are in agreement with those obtained and published by other authors in the literature. We validate our results because the theoretical study is in good agreement with the experimental study.

\section{Conflicts of Interest}

The authors declare no conflicts of interest regarding the publication of this paper.

\section{References}

[1] Lederhander, S.R and Giacoletto, L.J. (1955) Measurement of Minority Carrier Life- 
time and Surface Effects in Junction Devices. Proceedings of the IRE, 43, 477-483, https://doi.org/10.1109/JRPROC.1955.277857

[2] Kingston, R.H. (1954) Switching Time in Junction Diodes and Junction Transistors. Proceedings of the IRE, 42, 829-834. https://doi.org/10.1109/JRPROC.1954.274521

[3] Dean, R.H. and Nusese, C.J. (1971) A Refined Step-Recovery Technique for Measuring Minority Carrier Lifetimes and Related Parameters in Asymmetric p-n Junction Diodes. IEEE Transactions on Electron Devices, 18, 151-158. https://doi.org/10.1109/T-ED.1971.17167

[4] Reynolds, J.H. and Meulenberg Jr., A. (1974) Measurement of Diffusion Length in Solar Cells. Journal of Applied Physics, 45, 2582. https://doi.org/10.1063/1.1663633

[5] Gossick , B.R. (1955) On the Transient Behavior of Semiconductor Rectifiers. Journal of Applied Physics, 26, 1356. https://doi.org/10.1063/1.1721908

[6] Agarwal, S.K., Muralidharan, R. and Jain, S.C. (1981) Determination of the Minority Carrier Lifetime in the Base of a Back-Surface Field Solar Cell by Forward Current Induced Voltage Decay and Photo Volatage Decay Method. International Workshop on Physics of Semiconductor Devices, Delhi, 23-28 November 1981.

[7] Mahan, J.E., Eksted, T.W., Franck, R.I. and Kaplow, R. (1979) Measurement of Minority Carrier Lifetime in Solar Cells from Photo-Induced Open-Circuit Voltage Decay. IEEE Transactions on Electron Devices, 26, 733-739.

https://doi.org/10.1109/T-ED.1979.19487

[8] Gossick, B.R. (1953) Post-Injection Barrier Electromotive Force of p-n Junctions. Physical Review Journals Archive, 91, 1012.

https://doi.org/10.1103/PhysRev.91.1012

[9] Sam, R., Zouma, B., Zougmoré, F., Koalaga, Z., Zoungrana M. and Zerbo. I. (2012) 3D Determination of the Minority Carrier Lifetime and the p-n Junction Recombination Velocity of a Polycrystalline Silicon Solar Cell. IOP Conference Series. Materials Science and Engineering, Ouagadougou, 17-22 October 2011, 1-8. https://doi.org/10.1088/1757-899X/29/1/012018

[10] Sam, R., Kaboré, K. and Zougmoré, F. (2016) A Three-Dimensional Transient Study of a Polycritsalline Silicon Solar Cell under Constant Magnetic Field. International Journal of Engineering Research, 5, 93-97.

[11] Diasso, A., Sam R. and Zougmoré, F. (2020) External Magnetic Field and Air Mass Effects on Carrier's Effective Lifetime of a Bifacial Solar Cell under Transient State. Research Journal of Applied Sciences, Engineering and Technology, 17, 140-146. https://doi.org/10.19026/rjaset.17.6026

[12] Muralidharan, R. and Jain, S.C. (1982) Determination of the Minority Carrier Lifetime in the Base of a Back-Surface Field Solar Cell by Forward Current-Induced Voltage Decay and Photovoltage Decay Methods. Solar Cells, 6, 157-176. https://doi.org/10.1016/0379-6787(82)90064-3

[13] Dhariwhal, S.R. and Vasu, N.K. (1981) A Generalised Approach to Lifetime Measurement in pn Junction Solar Cells. Solid-State Electronics, 24, 915-927. https://doi.org/10.1016/0038-1101(81)90112-X

[14] Diasso, A., Sam, R., Yacouba, N.T. and Zougmoré, F. (2020) Effects of External Magnetic Field and Air Mass on Space Charge Width Extension of a Bifacial Solar Cell Front Side Illumination. International Journal of Energy and Power Engineering, 9, 29-34. 